\title{
Pancreatic Mucinous Cystadenoma Mimicking Intraductal Papillary Mucinous Neoplasm
}

\author{
Susana Marques Joana Carmo Miguel Bispo \\ Department of Gastroenterology, Centro Hospitalar Lisboa Ocidental, Lisbon, Portugal
}

\section{Keywords}

Acute pancreatitis · Ultrasound endoscopy

\section{Cistadenoma Mucinoso Mimetizando Neoplasia Mucinosa Papilar Intraductal do Pâncreas}

\section{Palavras Chave}

Pancreatite aguda · Ultrassonografia endoscópica

A 61-year-old female patient presented with epigastric pain radiating to the back for the previous 2 days. Physical examination revealed diffuse abdominal pain with epigastric tenderness. Laboratory results showed elevated lipase (2,946 UI/L). At this point, the diagnosis of acute pancreatitis (AP) was established. Abdominal ultrasonography and computed tomography revealed cystic pancreatic lesions arising from the head, body, and tail of the pancreas, ranging from 1 to $5.5 \mathrm{~cm}$ (Fig. 1a), with no evidence favoring a biliary cause for the AP. The patient was kept on n.p.o. and i.v. vigorous hydration and pain medication were provided. The clinical evolution was favorable and the patient was discharged after a 3-day hos-

\section{KARGER}

E-Mail karger@karger.com www.karger.com/pjg (c) 2017 Sociedade Portuguesa de Gastrenterologia Published by S. Karger AG, Basel Karcer Open access

This article is licensed under the Creative Commons AttributionNonCommercial-NoDerivatives 4.0 International License (CC BYNC-ND) (http://www.karger.com/Services/OpenAccessLicense) Usage and distribution for commercial purposes as well as any distribution of modified material requires written permission. pital stay. Two weeks after discharge, an endoscopic ultrasound (EUS) was performed and showed 4 pancreatic cystic lesions, 2 arising from the head, 1 from the body, and 1 from the tail, ranging from 5 to $55 \mathrm{~mm}$ and apparently all communicating with the main pancreatic duct, which was not dilated. Echogenic debris were observed inside the largest cystic lesion (Fig. 1b). A transgastric EUS-fine needle aspiration of the largest cyst was performed and revealed high amylase $(>48,000 \mathrm{UI} / \mathrm{L})$ and CEA $(291 \mathrm{ng} / \mathrm{mL})$ levels and clusters of mucinous epithelial cells, without atypia (Fig. 1c). All imaging, laboratory, and pathological findings were consistent with the diagnosis of a multifocal branch duct intraductal papillary mucinous neoplasm (IPMN). Due to the size of the largest cyst $(\geq 3 \mathrm{~cm}$ ) and the clinical presentation (pancreatitis), both worrisome features [1], the patient underwent a distal pancreatectomy. Unexpectedly, the final pathology diagnosis revealed a mucinous cystadenoma of the pancreatic body and tail with focal high-grade dysplasia. The patient remains under surveillance for the other cysts, with morphologic characteristics of branch duct IPMN.

IPMN and mucinous cystic neoplasia $(\mathrm{MCN})$ are two different types of mucinous cystic pancreatic neoplasms and may present as AP due to obstruction of the main 

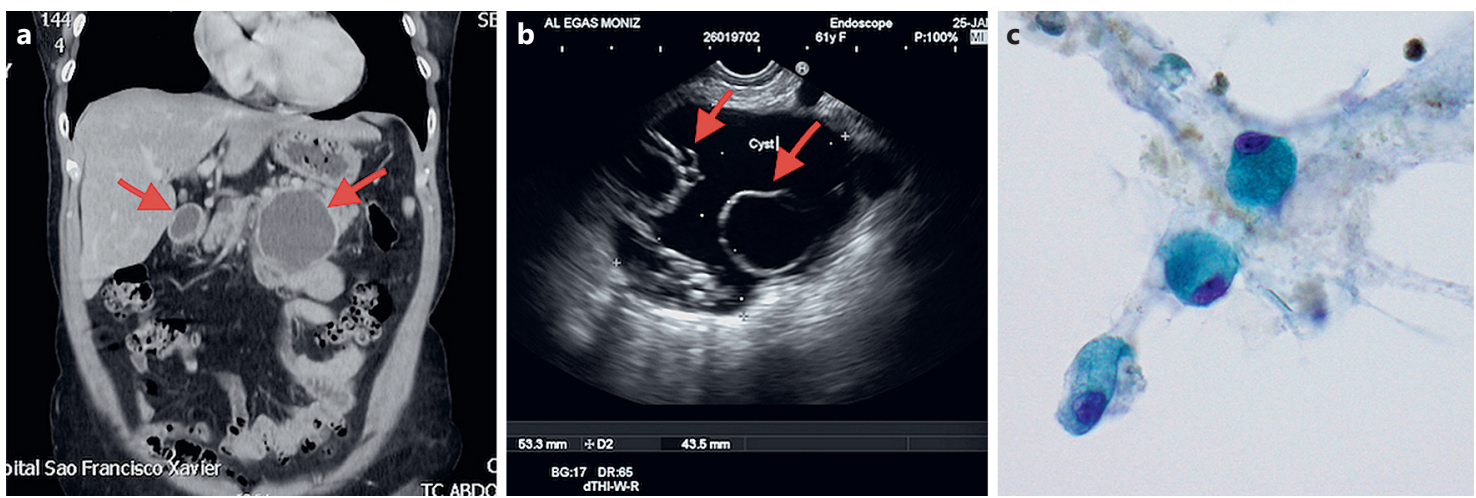

Fig. 1. a Abdominal computed tomography (coronal view): 2 cystic lesions, 1 arising from the head and 1 from the body of the pancreas (arrows). b EUS (transgastric view): large cystic lesion located in the pancreatic body, $55 \mathrm{~mm}$ in size, with echogenic debris (arrows). c Cystic fluid cytology: clusters of mucinous epithelial cells, without atypia. Papanicolaou. $\times 400$.

pancreatic duct by thick mucus secretion. In both lesions, EUS-guided cyst aspirate is typically viscous and characterized by the presence of columnar or cuboidal mucinous epithelial cells in pathology and high CEA levels in chemistry analysis. The presence of an ovarian-like stro$\mathrm{ma}$ is a unique pathological feature of MCN. IPMN has no gender predilection, is more common in the pancreatic head, and may be multifocal. On the contrary, MCN occurs almost exclusively in women (98\%) and is usually a single lesion located in the body and tail of the pancreas (95\%). Because IPMN communicates with the main pancreatic duct and MCN typically does not, the amylase fluid level is expected to be high in IPMN and within the normal range in $\mathrm{MCN}$ [1]. Despite distinct demographic, imaging, and laboratory features, distinguishing between an IPMN and a MCN is sometimes difficult. Up to $7 \%$ of MCNs communicate with the pancreatic duct due to the development of a fistula between the cyst and the pancreatic duct. In this very rare situation, an MCN may have high amylase level and be therefore misdiagnosed as an IPMN, such as happened in this case [2].

\section{Statement of Ethics}

This study did not require informed consent nor review/approval by the appropriate ethics committee.

\section{Disclosure Statement}

The authors have no conflicts of interest to declare.

\section{References}

1 Tanaka M, Castillo CF, Adsay V, Chari S, Falconi M, Jang JY, et al: International consensus guidelines 2012 for the management of IPMN and MCN of the pancreas. Pancreatology 2012;12:183-197.

2 Morel A, Marteau V, Chambon E, Gayet B, Zins M: Pancreatic mucinous cystadenoma communicating with the main pancreatic duct on MRI. BR J Radiol 2009;82:e243-e245. 